\title{
SESAJI KUPAT DALAM TRADISI GUMBREGAN DI DESA KEMIRI KECAMATAN TANJUNGSARI KABUPATEN GUNUNGKIDUL ${ }^{1}$
}

\author{
Ida Sulastri dan Suharti \\ Fakultas Bahasa dan Seni Universitas Negeri Yogyakarta \\ email: ida.idasulastri@gmail.com
}

\begin{abstract}
Abstrak: Sesaji Kupat dalam Tradisi Gumbregan di Desa Kemiri Kecamatan Tanjungsari Kabupaten Gunungkidul. Penelitian ini bertujuan mendeskripsikan makna simbolik dan manfaat sesaji kupat dalam tradisi Gumbregan. Penelitian ini menggunakan metode penelitian kualitatif. Pengumpulan data dilakukan dengan pengamatan berperan serta dan wawancara mendalam. Data dianalisis dengan teknik induktif dan keabsahan data dengan triangulasi sumber dan metode. Hasil penelitian menunjukkan bahwa pertama, sesaji kupat adalah salah satu bagian sesaji yang digunakan dalam tradisi berujud kelonthongan yang dibuat dari anyaman janur yang diisi beras, direbus sampai matang digunakan pada acara makan ternak dan kendhuren. Sesaji kupat digunakan pada ritual makan ternak atau sapi pada saat ngalungi sapi, makani sapi, dan masang kupat di kandhang. Sesaji kupat yang digunakan pada ritual kendhuren adalah kupat luwar. Kedua, makna simbolik sesaji kupat yang digunakan pada acara makan ternak dan kendhuren, untuk ngluwari ujar pemilik ternak karena ternaknya selamat, ndrebala, dan selanjutnya pemilik dan ternaknya dijauhkan dari gangguan apapun, selalu mendapat lindungan dari Tuhan Yang Maha Esa. Ketiga, manfaat kupat pada tradisi Gumbregan bagi masyarakat pendukungnya yaitu: (a) manfaat spiritual, (b) manfaat sosial, dan (c) manfaat pelestari tradisi.
\end{abstract}

Kata kunci: sesaji kupat, tradisi ternak, tradisi Gumbregan

\begin{abstract}
Sesaji Kupat in Gumbregan Tradition held in Kemiri Village, Tanjungsari, Gunungkidul. This study was aimed at describing the symbolic meaning and the benefits of the sesaji kupat in Gumbregan tradition. This study used qualitative research method. The data collection was conducted through participant observation and in-depth interviews. The data were analyzed using inductive technique and validated using triangulation source and method. The results show that first, sesaji kupat is one part of offerings that used in the tradition in the form of kelonthongan which are made from woven janur (woven coconut leaves) filled with rice, then boiled until cooked. It is used in livestock and kendhuren rituals. Sesaji kupat is used in the ritual of feeding and slaughtering livestock such as cows, while sesaji kupat used in kendhuren rituals is named as kupat luwar. Secondly, the symbolic meaning of sesaji kupat used in livestock and kendhuren is to "ngluwari ujar" or as agratitude expression of the owner because the livestock is safe and healthy, and hopefully the owner
\end{abstract}

1 Pengembangan dari penelitian berjudul "Tradhisi Gumbregan ing Desa Kemiri Kecamatan Tanjungsari Kabupaten Gunungkidul" 
and his livestock are kept away from any disturbance, and always protected by God Almighty. Third, the benefits of sesaji kupat in Gumbregan tradition for the communities are includes: (a) spiritual benefits, (b) social benefits, and (c) traditional preservation.

Keywords: sesaji kupat. livestock tradition, Gumbregan tradition

\section{PENDAHULUAN}

Kabupaten Gunungkidul salah satu kabupaten di Daerah Istimewa Yogyakarta yang terkenal akan tradisinya. Tradisi sebagai bagian dari kebudayaan, memberikan gambaran yang mengkhusus, yang dapat dikatakan sebagai identitas Kabupaten Gunung Kidul. Masyarakat Gunung Kidul termasuk mayarakat yang masih taat dan menghormati kepada leluhurnya. Ketaatan dan penghormatan terhadap lelehurnya tersebut diwujudkan dengan menjalankan segala tradisi yang dilakukan oleh para leluhurnya. Kegiatan yang dilakukan oleh masyarakat Gunung Kidul ini sesuai dengan pernyataan Danandjaya bahwa kebudayaan kolektif yang tersebar dan diwariskan secara turun-temurun secara tradisional dengan versi yang berbeda disertai gerak isyarat atau alat bantu pengingat (Danandjaja, 1986: 2). Salah satu adat tradisi yang masih dilaksanakan hingga saat ini oleh sebagian besar masyarakat Gunungkidul yaitu tradisi Gumbregan.

Gumbregan berasal dari kata gumbreg mendapat imbuhan -an. Gumbreg adalah salah satu nama wuku yang memiliki usia atau lama waktu tujuh hari. Pawukon adalah perhitungan hal wuku beserta keterangannya tentang begja dan cilakaning wong 'nasib baik dan nasib buruk seseorang' (Poerwadarminto, 1939: 433). Wuku merupakan bagian dari siklus di dalam penanggalan Jawa dan Bali berjumlah 30 (Moertjipto dkk., 1996-1997: 45). Gumbreg merupakan wuku keenam.
Gumbregan dilaksanakan di setiap Wuku Gumbreg sehingga dinamakan tradisi Gumbregan. Gumbregan ini dapat disebut tradisi karena merupakan tata kelakuan berdasarkan ide-ide sesuai norma-norma yang berlaku pada aturan setempat dan bersifat konkret (Herusatoto, 2008: 164 -165).

Gumbregan ini termasuk tradisi kecil yang memiliki keunikan tersendiri. Keunikannya, tradisi ini dilaksanakan untuk selamatan hewan yakni sapi. Hewan sapi dianggap berjasa dan bermanfaat bagi warga masyarakat Gunung kidul karena dapat membantu perekonomian warga dan membantu dalam hal pertanian, seperti membajak sawah yang dalam istilah Jawa disebut 'ngluku' atau 'nggaru'. Selain itu, kotorannya juga bisa dijadikan sebagai pupuk tanaman. Tradisi ini dilaksanakan dengan berbagai sesaji sebagai simbol untuk menyatakan rasa sukur dan harapan-harapan bagi masyarakat pendukungnya.

Tradisi Gumbregan ini diadakan karena berhubungan dengan kepercayaan masyarakat bahwa semua hewan yang ada di dunia ini ada yang merajainya, yaitu Nabi Sulaiman. Oleh karena itu, pada setiap Wuku Gumbreg warga masyarakat Gunungkidul yang memiliki ternak sapi melakukan selamatan agar sapinya selalu sehat, dapat berkembang biak dengan baik, dan dapat membantu perekonomian masyarakat pendukung serta membantu dalam hal pertanian. Selamatan ini dilaksanakan sebagai sarana 
untuk mewujudkan rasa syukur warga masyarakat kepada Tuhan Yang Maha Esa atas limpahan rezeki yang diberikan dari hasil ternak sapi dan dari hasil pertanian. Selain itu, tradisi ini juga sebagai sarana untuk mewujudkan rasa syukur dan terima kasih kepada Nabi Sulaiman yang telah mengizinkan hewan sapinya dipelihara oleh seluruh manusia di dunia, khususnya di Gunungkidul. Harapannya, dengan melaksanakan tradisi selamatan ini, kehidupan sehari-hari masyarakat pendukung terhindar dari segala bahaya apapun.

Tradisi Gumbregan sudah dilakukan secara turun-temurun oleh warga Gunung Kidul (Danandjaja, 1986: 1-2). Pelaksanaan tradisi Gumbregan ini sejak dari leluhurnya, terdiri dari dua bagian kegiatan, yaitu persiapan dan pelaksanaan Gumbregan. Persiapan menyakup persiapan sesaji makan sapi dan kendhuren sedangkan pelaksanaannya yaitu acara ritual makan ternak dan kendhuren Gumbregan. Sesaji makan ternak terdiri dari jadah woran, kupat (luwar, lepet, cepuk dan bojo lima), pulo, katul dan boreh sedangkan sesaji kendhuren adalah jadah woran, kupat, dan pulo. Dari kedua pelaksanaan Gumbregan, sesaji yang sama dan penyiapannya lebih lama adalah sesaji kupat. Untuk itu pada kesempatan ini akan dibicarakan (1) apa dan bagaimana kupat luwar, lepet, cepuk, dan bojo lima, (2) bagaimanakah makna sesaji kupat luwar, lepet, cepuk, dan bojo lima, sebagai bagian dari sesaji Gumbregan, dan (3) manfaat dari sesaji kupat bagi masyarakat pendukungnya.

\section{METODE}

Penelitian ini menggunakan pendekatan kualitatif. Pendekatan kualitatif yang digunakan adalah kualitatif deskriptif, yaitu suatu penelitian yang bertujuan untuk mendeskripsikan gejala yang menjadi fokus penelitian. Data yang dihasilkan berupa kata-kata tertulis atau lisan dari orang-orang dan perilaku yang dapat diamati (Moleong, 2006: 4).

Lofland dan Lofland (Moleong, 2006: 157) menyatakan bahwa sumber data utama dalam penelitian kualitatif ialah kata-kata dan tindakan, selebihnya adalah data tambahan seperti dokumen dan lain-lain. Sumber data dalam penelitian ini adalah warga masyarakat Desa Kemiri yang paham tentang Gumbregan dan yang ikut serta atau terjun langsung ke lapangan sebagai pelaku utama tradisi Gumbregan ini. Warga desa tersebut adalah sesepuh desa, kaum kendhuren atau orang yang memimpin kendhuren, pamong desa, dan warga masarakat Desa Kemiri yang melaksanakan tradisi Gumbregan.

Metode yang digunakan untuk menentukan informan yaitu dengan teknik purposive sampling. Moleong (2006: 224) menyebutkan bahwa teknik purposif adalah memilih informan dengan cara memilih orang-orang yang bisa memberi data akurat. Data akurat dapat ditemukan dengan memilih informan kunci yang dapat memberikan informasi secara akurat dan dapat memberikan penjelasan untuk menentukan informan lainnya untuk mendapatkan data penelitian sesuai dengan fokus yang sudah ditentukan.

Teknik pengumpulan data yang digunakan adalah pengamatan berperanserta dan wawancara mendalam. Pengamatan berperanserta digunakan untuk mengumpulkan data berupa peristiwa jalannya Gumbregan yang dilaksanakan oleh warga Kemiri. Wawancara mendalam dilakukan untuk mendapatkan penjelasan tentang segala sesuatu yang terkait dengan jalannya Gumbregan. Data dianalisis menggunakan teknik analisis induktif. Pengesahan data menggunakan teknik triangulasi sumber dan metode. 
Penelitian ini dilaksanakan di Desa Kemiri, Kecamatan Tanjungsari, Kabupaten Gunungkidul. Tradisi Gumbregan di Desa Kemiri ini dilaksanakan setiap Wuku Gumbreg di hari Selasa Wage dan Kemis Legi. Masyarakat pendukung tradisi ini adalah seluruh warga masyarakat Desa Kemiri yang ngingu 'memelihara' hewan sapi.

\section{HASIL DAN PEMBAHASAN}

Tradisi Gumbregan diadakan di Desa Kemiri, Kecamatan Tanjungsari, Kabupaten Gunung Kidul. Tradisi Gumbregan dilaksanakan pada Wuku Gumbreg oleh yang ngingu 'memelihara' sapi. Para warga melaksanakan gumbregan didasarkan pada yang telah dilakukan oleh leluhurnya bahwa sapi yang dipeliharanya nggadhuh dari yang menguasai sapi yaitu Nabi Sulaiman. Gumbregan yang selalu dilakukan warga Desa Kemiri ini menunjukkan bahwa warga tersebut merupakan penjaga tradisi yang sangat kuat (Mulyani, dkk. 2016: 75). Warga yang menjaga kuat tradisinya ini didukung oleh pernyataan informan 02 berikut.

"... nek gumbregan niku riyin-riyine gandheng tiyang-tiyang niku sami ngingah sato kewan nek miturut sejarah kuna sapi niku sipate ming nggadhuh, dadi nek sato kewan niku onten sing nguwasani, dadi critane niku napa leres napa boten sik nguwasani sato kewan niu Kyai Nabi Suleman, mulane samben wuku Gumbreg niku di gumbregi, diwilujengi. Wilujengan niku gumbregan, dadi saben dhawah Wuku Gumbregg di wilujengi ngoten, nek cara mriki nggih niku kupatan kalih palawija, napa ketan napa nggih napa ontene" (CLW 02).

... kalau gumbregan itu dulu-dulunya karena orang-orang itu pada memelihara hewan kalau menurut sejarah kuna sapi iti sifatnya hanya titipan, jadi hewan itu yang memiliki itu Kyai Nabi
Suleman, maka setiap Wuku Gumbreg diselamati. Selamatan itu gumbregan, jadi setiap jatuh pada Wuku Gumbreg diselamati begitu, kalau cara di sini ya itu kupatan dengan palawija, ketan, apa ya seadanya' (CLW 02),

Tradisi Gumbregan dilaksanakan selama satu hari, dari pagi sampai sesudah magrib. Pelaksanaan prosesi tradisi Gumbregan dibedakan menjadi dua kegiatan yakni persiapan sesaji dan pelaksanaan inti tradisi Gumbregan. Sesaji yang dipersiapkan yakni kupat, jadah woran, pulo, air tawar, dan boreh untuk ritual makan sapi, serta kendhuren Gumbregan. Pelaksana tradisi Gumbregan adalah warga yang memiliki dan atau ngingu 'memelihara' sapi.

Persiapan sesaji dimulai pada pukul 06.00 WIB yakni sesaji makan sapi dan sesaji kendhuren. Sesaji makan sapi terdiri dari empat macam kupat,jadah woran, pulo, katul dan boreh sedang sesaji kendhuren terdiri atas, empat macam kupat, jadah woran, dan pulo. Warga menyiapkan sesaji di rumahnya masing-masing. Pada sore hari pukul 16.00 WIB para pemilik sapi, mulai melaksanakan prosesi inti Gumbregan yang pertama yaitu makan sapi terdiri atas: makani sapi, ngalungi sapi, dan masang kupat di kandhang sapi masing-masing. Acara selanjutnya sesudah Magrib, warga mengadakan kendhuren di rumah Bapak RT atau Bapak Kepala Dukuh atau di Bale Padukuhan. Penjelasan ini didukung pernyataan informan 01 .

"Dalam acara Gumbregan, pertama, itu dari pagi sampai siang menyediakan sesaji untuk ritual makan ternak dan untuk kenduri. Kedua, sore sekitar jam empat atau lima itu menika makan ternaknya, yang pokok ngekekne ten sapine nggih sing duwe sapi. Terus yang terakhir sekitar habis Magrib itu kenduri". 
Gumbregan dilaksanakan satu hari dari pukul 06.00 WIB sampai sesudah Magrib, pada hari Selasa Wage dan Kamis Lagi. Seperti yang dituturkan oleh informan berikut.

"... nek gumbregan kalih dinten sing diangge niku, Selasa Wage malem Rebo Kliwon kalih Kemis Legi malem Jemuah Paing ..."

'... kalau gumbregan dua hari yang digunakan itu, Selasa Wage malam Rabu Kliwon dan Kamis Legi malam Jumat Paing ....

Jadi Sesaji Gumbregan dibedakan menjadi dua yakni sesaji makan sapi dan sesaji kendhuren. Sesaji makan ternak terdiri atas pakan ternak dan boreh. Pakan ternak terdiri atas: jadah woran, kupat empat macam, pulo, dan katul. Boreh terdiri atas: daun kemuning, irisan daun pandan, bunga mawar, dan kapur sirih. Adapun sesaji kendhuren sama dengan sesaji pakan sapi, tetapi tidak menggunakan katul dan boreh. Yang menarik pada sesaji gumbregan ini adalah sesaji kupat yang digunakan pada acara makan sapi dan kendhuren. Pada kesempatan ini akan dibicarakan secara berurutan tentang penyiapan sesaji kupat, pelaksanaan tradisi Gumbregan dengan urutan makan sapi dan kendhuren.

Penyiapan Sesaji kupat ada empat macam. Keempat jenis kupat tersebut digunakan sebagai sesaji selama pelaksanaan acara tradisi Gumbregan, yaitu sebagai sesaji ritual makan sapi dan sesaji kendhuren. Penyiapan sesaji kupat ini dimulai dengan membuat kulit kupat atau disebut klonthongan kupat. Klonthongan kupat dibuat dari daun kelapa yang masih muda disebut janur. Klonthongan diisi beras. Beras yang diisikan di klonthongan kupat, sebelumnya dicuci bersih, ditiriskan, kemudian baru diisikan ke dalam klonthongan kupat. Pengisian beras kira-kira setengah dari besarnya klonthongan kupat agar nantinya kupat dapat matang dengan sempurna. Klonthongan kupat luwar, lepet, cepuk, dan bojo lima seperti Gambar 1.

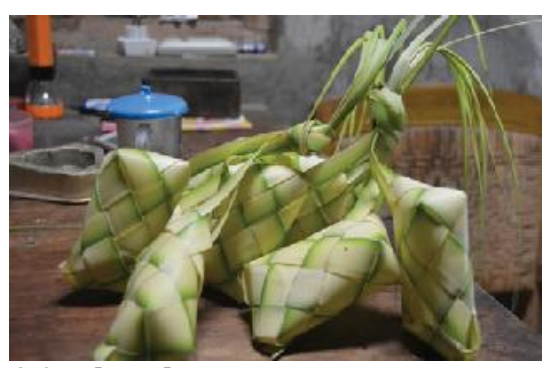

(a) Klonthongan Kupat Luwar

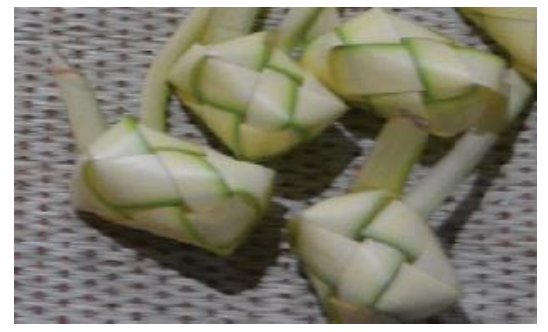

(c) Klonthongan Kupat Cepuk

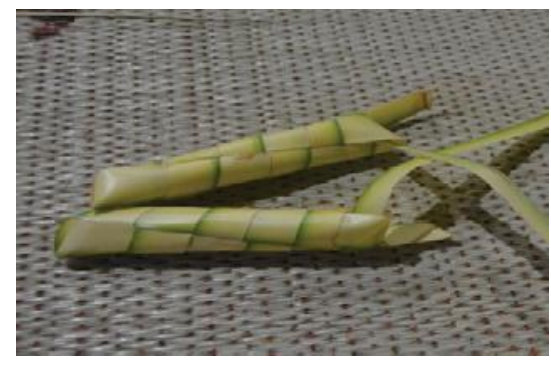

(b) Klonthongan Kupat Lepet

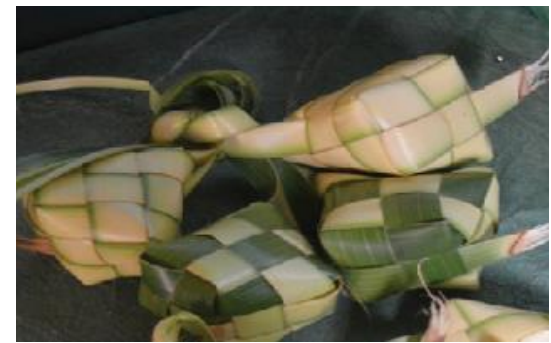

(d) Klonthongan kupat bojo lima

Gambar 1. Macam-macam Klonthongan Kupat 
Klonthongan kupat sesudah diisi beras kemudian direbus kira-kira empat jam sampai matang. Pembuatan sesaji ini dilaksanakan secara pribadi di rumah masyarakat pendukung masing-masing. Berikut adalah sesaji kupat yakni kupat luwar, kupat lepet, kupat cepuk, dan kupat bojo lima, yang sudah siap ditata sebagai sesaji tradisi Gumbregan pada ritual makan sapi dan kendhuren. Pembuatan ketiga jenis kupat ini tidak sebanyak kupat luwar, karena sesaji hanya digunakan sebagai sesaji yang ditujukan kepada para leluhur, tidak bisa dimakan oleh hewan ternak ataupun pemiliknya. Gambar 2 adalah sesaji kupat yang siap ditata untuk sesaji makan ternak sapi dan kendhuren gumbregan.

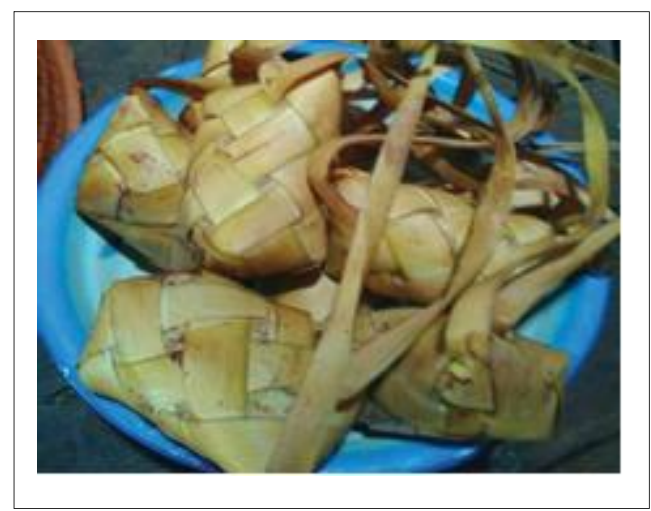

Gambar 2. Sesaji Kupat

Sesaji kupat setelah matang dipersiapkan yang pertama adalah ritual makan sapi. Ritual makan sapi terdiri dari ngalungi sapi, makani sapi dan masang kupat di kandhang sapi, yang sebelumnya sudah dilakukan acara-acara pendahuluannya yakni nggebyur, mborehi, dan ndhadhung sapi.

Ritual ngalungi sapi dilakukan oleh pemilik sapi, dilaksanakan pada sore hari kira-kira pukul 16.00 WIB dan kupat yang digunakan untuk ngalungi sapi adalah kupat luwar sejodho 'dua buah ketupat'. Kupat luwar sejodho 'ketupat dua buah' dikalungke di leher sapi. Tujuan sapi dikalungi kupat luwar sebagai bentuk dan wujud tindakan nyata pengesahan bahwa sang pemilik sapi sangat menyayangi hewan ternaknya dan juga sebagai ucapan rasa terima kasih sang pemilik karena ternaknya sudah memberikan banyak bantuan ataupun manfaat dalam hal pertanian ataupun perekonomian. Selain itu, ritual ngalungi sapi bertujuan untuk mageri atau mbentengi sapi agar selalu dilindungi oleh makhluk yang berada di sekelilingnya. Sapi selalu membantu dalam hal pertanian, karena sapi dapat digunakan untuk membacak sawah dalam bahasa Jawa disebut ngluku - nggaru dan tlethong 'kotoran sapi' dapat digunakan sebagai pupuk tanaman. Gambar 3 adalah sapi yang telah selesai dilakukan ritual ngalungi sapi.

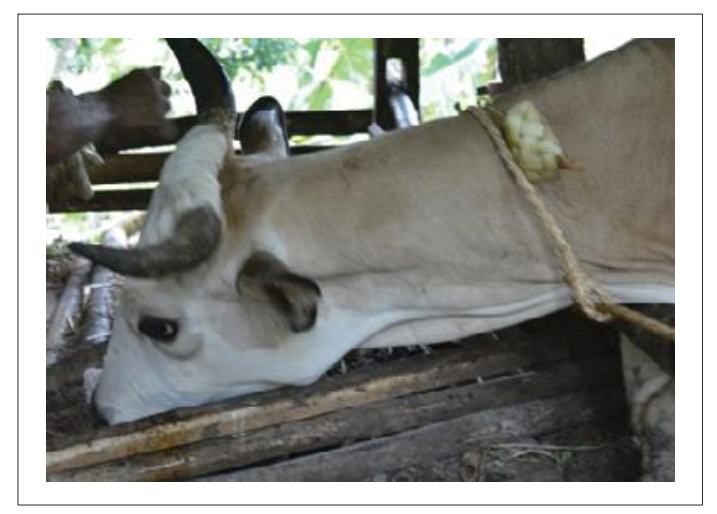

Gambar 3. Ngalungi Sapi

Selesai pelaksanaan ritual ngalungi sapi, acara berikutnya adalah ritual makani sapi. Ritual makani sapi dilaksanakan setelah selesai ritual ngalungi sapi. Makani sapi dilakukan oleh pemilik sapi atau pemilik sapi dapat minta tolong kepada tetangganya. Sesaji pakan sapi berujud jadah woran, kupat, pulo, dan katul ditambah sekar boreh, enjet, toya tawa. Sesaji pakan yang terdiri dari kupat dan lain-lain seperti dikemukakan oleh informan 01. 
"Pertama itu dari pagi sampai siang menyediakan untuk pakan ternak itu ada katul, terus ada kupat..." (CLW 01)

Pernyataan itu juga disampaikan oleh informan lainnya, seperti berikut.

"Sarat-sarate nggih niku gawe kupat werna papat: kupat luwar, kupat lepet, kupat cepuk, karo kupat sompil, terus gawe pulo, aja lali kembang boreh e karo dhadhung anyar e." (CLW 05).

'sesaji-nya itu membuat ketupat empat macam yaitu kupat luwar, kupat lepet, kupat cepuk, dengan kupat sompil ...' (CLW 05).

Pada ritual makani sapi didahului dengan berdoa, dan wujud doa antara pemilik sapi satu dengan lainnya tidak sama. Doa tersebut berisi permohonan dari keluarga pemilik sapi kepada Tuhan yang Maha Pengasih agar sapi ingoningone 'sapi peliharaannya' itu selamat, dijauhkan dari semua bahaya apapun, seperti dituturkan oleh informan 02 berikut.

“... Donga menika saben tiyang boten sami, nggih ming sak saged $e$ piyambak, miturut lelurine jaman riyin, ingkang cetha nyuwun kajenge sapi menika saged ngerda widada kalis saking sedaya rubeda napa mawon. Penuwunane ngoten niku, dadi kula niku ming kari nglestarikake adat" (CLW 02).

'... Doa itu setiap orang tidak sama, ya sedapatnya masing-masing, menurut leluhurnya jaman dulu, yangg jelas memohon supaya sapi-nya dapat berkembang biak dengan baik, sehat, dijauhkan dari mara bahaya apapun. Permohonannya seperti itu, jadi saya hanya tinggal melestarikan adat' (CLW 02).
Selain tujuan memohon keselamatan untuk sapi lan sing ngingu 'lembu dan pemeliharanya', dengan tradisi Gumbregan ritual makani sapi, pemelihara sapi mengharapkan supaya sapi yang digumbregi -dipakani kupat-menjadi gemuk, dan dapat menjadi tabungan untuk mencukupi segala kebutuhan. Pernyataan ini didukung penuturan informan 01 dan 05 seperti berikut.

“... Dipakani niku karepe ben lemu mbak. Nek pun lemu nggih terus harapane bisa berkembang biak, supaya bisa untuk membantu tani dan bisa untuk nyukupi butuh" (CLW 01). '... Diberi makan itu tujuannya supaya gemuk Mbak. Kalau sudah gemuk ya harapannya dapat berkembang biak, supaya dapat membantu petani dan dapat untuk memenuhi kebutuhan' (CLW 01).

Tuturan informan 05 seperti berikut ini.

“... Pi saiki tekan Wuku Gumbreg kowe diopahi menyang bendara Sira, panganen, nek wis entek sowana Nabimu Sulaiman, nek bali mampiro pasar mbalong nempura beras pari, jejerna genuke bendara sira, men nganti kebak ber luber kaya kali bengawan mili, nek manak lanang ngebakana kranjang nek manak wedok ngebakana kandhang ..." (CLW 05).

‘.. Pi sekarang sampai Wuku Gumbreg, kamu diberi upah oleh tuanmu, dimakan, kalau sudah habis menghadaplah ke Nabimu Sulaiman, kalau pulang mampir ke pasar Balong beli beras pari, jajarkan berdampingan dengan tempat beras tuanmu, biar sampai penuh meluber seperti mengalirnya kali bengawan. Kalau beranak jantan biar memenuhi 
kranjang kalau betina memenuhi kandhang..." (CLW 05).

Harapannya setelah diberi makan kupat luwar ini, sapi akan semakin gemuk, sehat, sehingga dapat ndrebala 'berkembang biak dengan baik'. Adapun sapi dapat membantu perekonomian karena beternak sapi dapat digunakan sebagai tabungan. Tabungan itu dapat diambil kapan saja dibutuhkan, misalnya sapi dijual, uang penjualan tidak diminta semua tetapi ditukar dengan sapi yang lebih kecil sesuai dengan keinginan pemilik sapi dan pemiliknya mendapat kelebihan uang penjualannya, ini biasa disebut pemilik sapi "ngereti". Gambar 4 adalah gambar pakan sapi 'makanan sapi' terdiri atas kupat luwar, katul, jadah woran, dan pulo.

Kupat lepet, cepuk, dan bojo lima ini merupakan sesaji dalam tradisi Gumbregan yang digunakan dalam ritual makan ternak. Kupat lepet, kupatcepuk, dan kupat bojo lima tidak diberikan sebagai pakan sapi, karena sesaji ini fungsinya adalah sebagai sesaji yang ditujukan kepada para leluhur, tidak bisa dimakan oleh hewan ternak ataupun pemiliknya. Dengan demikian, dapat disimpulkan bahwa pada ritual makani sapi, kupat yang digunakan adalah kupat luwar. Gambar 5 adalah gambar ritual makani sapi.

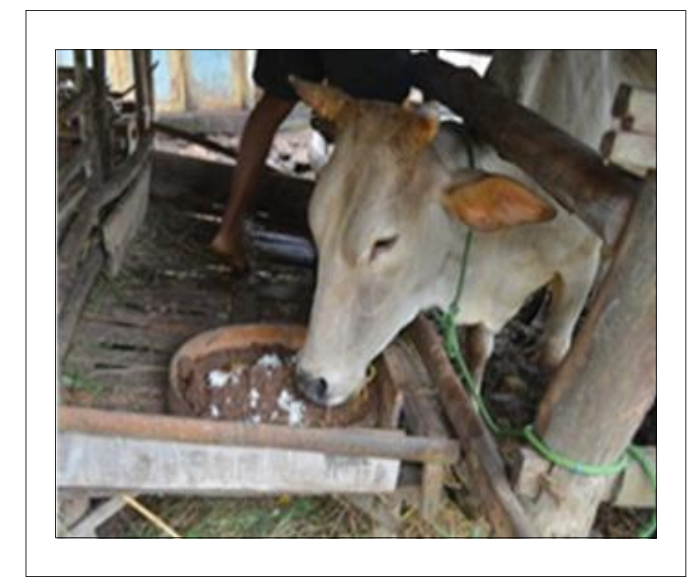

Gambar 5. Makani sapi

Sejalan dengan ritual ngalungi sapi yang menggunakan kupat luwar sebagai pager atau benteng supaya sapi tidak diganggu oleh bahaya apapun atau makhluk apapun dan juga sebagai pangluwar ujar dari pemelihara sapi, bahwa mereka sudah nggumbregi sapi peliharaannya.

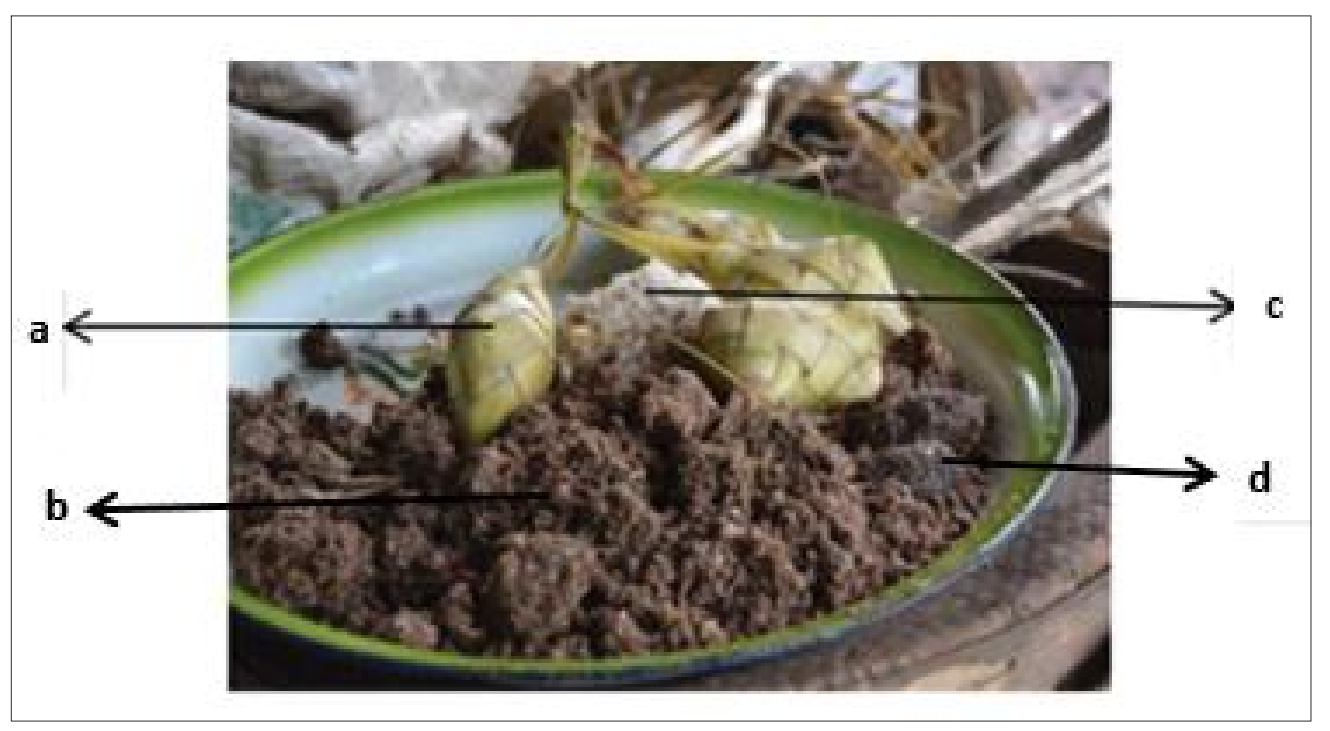

Gambar 4. Pakan Sapi: (a) Kupat Luwar, (b) Katul, (c) Jadah Woran, dan (d) Pulo 
'... maunya itu diberi makan supaya gemuk. Sesudah gemuk lalu dapat beranak banyak, kalau beranak betina itu supaya terus beranak sampai kandhang-nya tidak cukup, kalau beranak jantan biar sampai punuknya besar biar dapat digunakan untuk membeli tanah. Kalau sudah tambah tanahnya yang diharapkan panen padi banyak, tempat beras juraganmu tidak pernah kosong, penuh terus seperti sungai bengawan, terus-menerus isi tanpa berhenti. Jagungnya panen, padinya panen, sapi-nya beranak, semua kebutuhan tercukupi. Itu yang diharapkan sesepuh seperti itu (CLW 05).

Masang kupat dilaksanakan sesudah selesai ritual ngalungi sapi dan makani sapi. Masang kupat merupakan acara terakhir dari ritual makan sapi. Ritual makan sapi terakhir ini adalah para pemelihara sapi memasang kupat di kandhang-nya masing-masing. Ketupat yang dipasang di-kandhang sapi tersebut ada tiga macam ketupat, yakni kupat cepuk, lepet, dan bojo lima. Pemasangan ketupat kebanyakan di emperan kandhang sapi. Pemasangan ketupat tersebut sebetulnya tidak ada aturan harus di pasang di bagian tertentu, tetapi yang penting di pasang di kandhang para pemelihara sapi. Penjelasan ini sesuai dengan yang dituturkan oleh informan 02 berikut.

“... Nggih wonten kandhang niku, sik penting niku wonten kandhang. Niku kupat bojo limo, kupat cepuk, lan kupat lepet niku. Bibar masang kopat niku nggih sampun rampung anggene makani sapi niku" (CLW 02).

.... ya di pasang di kandhang itu, yang penting di kandhang. Itu kupat bojo lima, kupat cepuk, dan kupat lepet. Setelah memasang ketupat, ya sudah selesai acara makani sapi (CLW 02).
Tujuan masang kupat adalah untuk menyampaikan rasa terima kasih dari pemelihara sapi kepada yang menjaga sapi di kandhang. Masyarakat desa Kemiri percaya bahwa yang menjaga sapi adalah Nabi Sulaiman atau oleh masyarakat desa Kemiri dijuluki Kyai Bagus Lancur. Ritual masang kupat di kandhang seperti tertera pada Gambar 6 sudah selesai dilaksanakan, maka ritual makan sapi telah berakhir. Selanjutnya dilaksanakan ritual kendhuren Gumbregan.

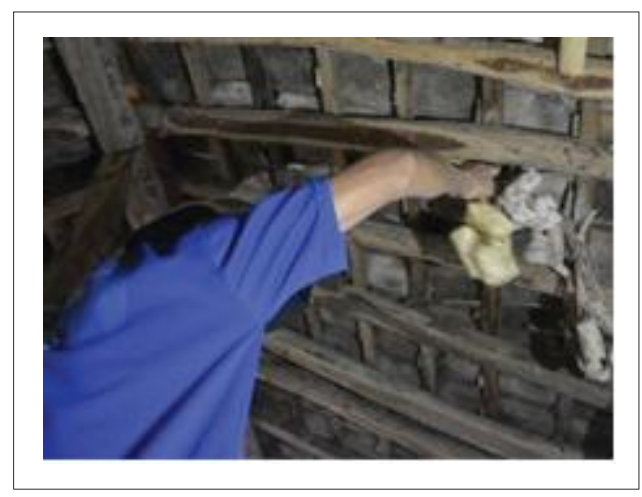

Gambar 6. Masang Kupat di Kandhang Sapi

Kendhuren Gumbregan dilaksanakan setelah ritual makani sapi, sesudah waktu Magrib. Sesudah Magrib warga berkumpul di tempat kendhuren gumbregan. Tempat kendhuren antara dusun satu dengan lainnya tidak sama, yakni ada yang bertempat di rumah Bapak RT, Bapak Dukuh atau di bale padukuhan. Adapun sesaji kendhuren Gumbregan adalah kupat luwar. Sesaji kupat luwar ini dijadikan dalam satu wadah bersama sesaji kendhuren yang lain, yaitu tumpeng jadah woran dan pulo, seperti Gambar 7.

Sesaji kupat luwar dalam kendhuren Gumbregan ini sebagai sarana untuk memperingati atau mengingat roh para leluhur yang ada di setiap dusun di Desa Kemiri. Sesaji kupat luwar ini juga sebagai wujud penghormatan kepada Nabi Sulaiman yang telah merajai 


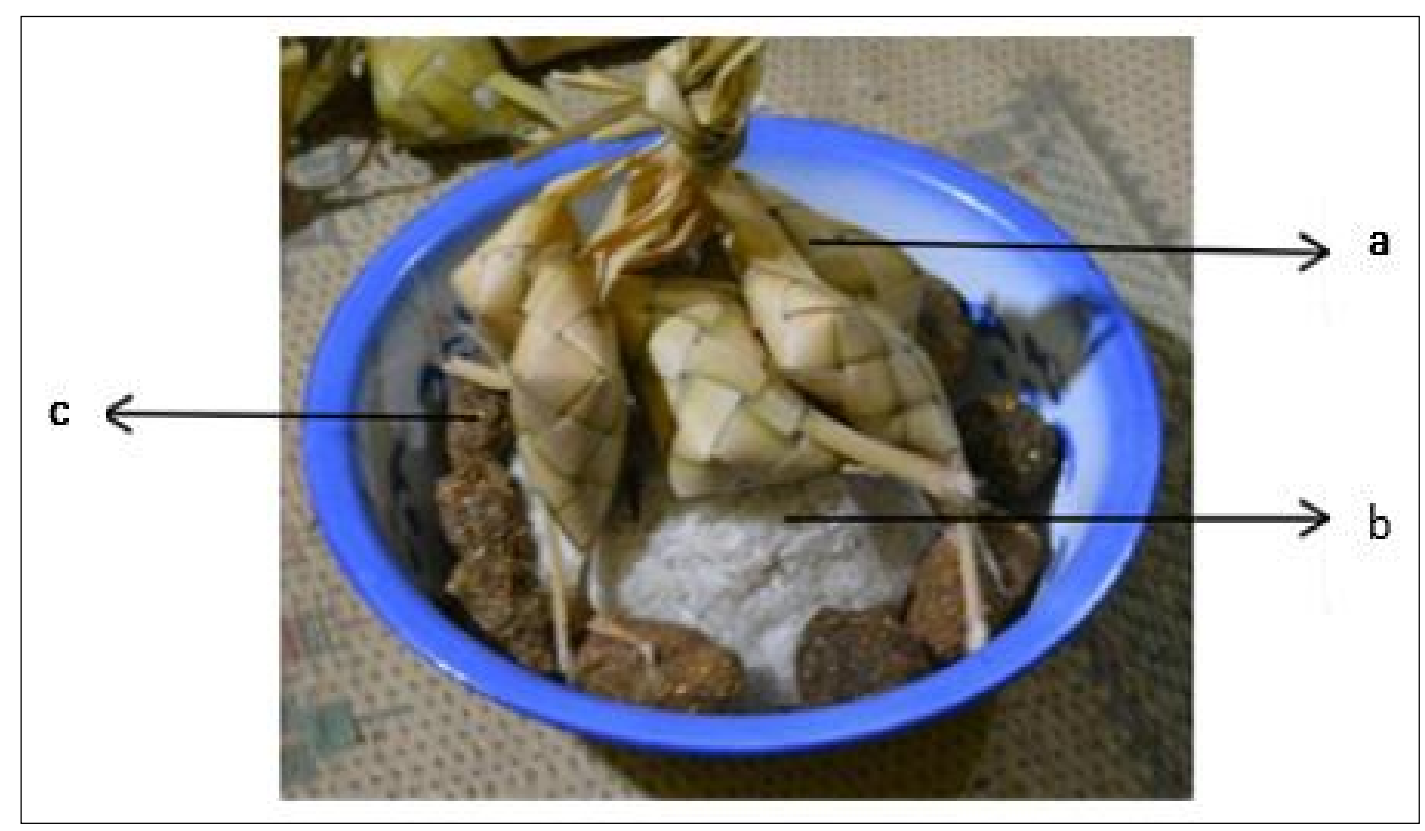

Gambar 7. Sesaji Kendhuren

(a) Kupat luwar, (b) Tumpeng Jadah Woran, dan (c) Pulo

seluruh hewan dan untuk mengingat atau menghormati para makhluk yang dapat mengganggu keselamatan ternak sapi seperti diungkapkan oleh informan.

Harapannya dengan melaksanakan tradisi Gumbregan dan mengadakan sesaji-sesaji itu semua hewan sapi milik masyarakat pendukung selalu sehat, subur, ndrebala 'dapat berkembang biak dengan baik', dan dijauhkan dari segala bahaya apapun, serta pertanian masyarakat pendukung senantiasa diberikan hasil yang memuaskan.

Sesaji kupat yang digunakan pada ritual makan ternak untuk ngluwari ujar pemilik ternak karena ternaknya selamat, sehat, gemuk, ndrebala 'berkembang biak dengan baik dan selanjutnya pemilik dan ternaknya dijauhkan dari gangguan apapun, selalu mendapat lindungan dari Tuhan Yang Maha Esa. Ketupat yang digunakan pada sesaji makan sapi dan kendhuren Gumbregan adalah kupatluwar, kupat lepet, kupat cepuk, dan kupat bojo lima.
"Tapi untuk kupat itu saya sedikit pernah mirengke, kupat kuwi isa nglumpatke bangsa pekewuhe, dalam arti maknane tiyang sepuh duka Mbak, mungkin nglumpatke bangsa pekewuhe itu maksudnya meminta selamat. Selamat untuk si hewan itu, selamat untuk pemeliharanya, dan pada akhirnya supaya hewan itu sehat dan dapat berkembang biak dengan bagus. Itu kupat kalau menurut saya seperti itu" (CLW 01).

Kecuali untuk ngluwari ujar atau nadar, kupat juga digunakan sarana untuk menyingkirkan segala bahaya agar selamat, baik sapi maupun pemeliharanya. Yang dimaksud mara bahaya adalah segala halangan berujud apa saja yang menyebabkan sengsara atau perasaan tidak enak (Poerwadarminta, 1939: 458). Kupat luwar yang dilingkarkan di leher sapi sebagai simbol untuk mageri atau mbentengi sapi supaya luwar dan dijauhkan dari segala mara bahaya 
berujud apapun yang dapat mengganggu keselamatan sapi dan keselamatan pemeliharanya.

Dalam hal ini, kupat luwar sebagai simbol pangluwar ujar atau nadar sang pemilik sapi. Artinya, sesaji kupat luwar ini menjadi simbol atau bukti sahnya suatu janji atau nadar atau ujar sang pemilik. Janji yang dimaksud yakni melaksanakan tradisi selamatan hewan setiap $W u k u$ Gumbreg. Selain itu, kupat luwar yang dilingkarkan ke leher sapi ini sebagai pagar atau bentengnya ternak sapi dari segala kekuatan yang dapat mengganggu ketentraman sapi. Harapannya, dengan ngalungi kupat luwar ini sapi akan terhindar dari segala mara bahaya apapun. Pernyataan ini didukung oleh tuturan informan 06 sebagai berikut.

“... kalung kuwi lak diubedake ing gulu. Ubed kuwi cara dene pager Mbak. Sapi dikalungi kupat luwar padha karone sapi dipageri kupat luwar. Dipegeri kupat luwar supayane luwar utawa adoh saka sakehing reribed sik isa nggodha sapi niku. Mula dilambangke yen gumbregan sapi dikalungi kupat, supaya apa, supayane slamet seka sakabehing reribed utawa alangan sik isa ngganggu tentreme sapi niku, ngoten Mbak larah-larahe" (CLW06). '... kalung itu kan dilingkarkan di leher. Dilingkarkan itu takubahnya pagar Mbak. Sapi dilingkari kupat luwar sama dengan sapi dikelilingi pagar kupat luwar. Dilingkari pagar kupat luwar supaya luwar 'bebas' atau jauh dari segala mara bahaya atau halangan yang dapat mengganggu ketentraman sapi itu, begitu Mbak ceritanya' (CLW 06).

Selain kupat luwar digunakan untuk ngalungi sapi juga untuk bukti pangluwar ujar atau nadar pemelihara sapi karena sapinya sehat, selamat, terbebas dari mara bahaya apapun, seperti dituturkan oleh informan 01 berikut.

"Tapi untuk kupat itu saya sedikit pernah mirengke, kupat kuwi isa nglumpatke bangsa pekewuhe, dalam arti maknane tiyang sepuh duka mbak, mungkin nglumpatke bangsa pekewuhe itu maksudnya meminta selamat. Selamat untuk si hewan itu, selamat untuk pemeliharanya, dan pada akhirnya supaya hewan itu sehat dan dapat berkembang biak dengan bagus. Itu kupat kalo menurut saya seperti itu" (CLW 01).

Pada ritual masang kupat digunakan jenis kupat lepet, kupat cepuk, dan kupat bojo lima, yang dipasangkan di kandhang sapi. Ketiga jenis sesaji kupat ini menyimbolkan wujud rasa terima kasih sang pemilik kepada makhluk yang menjaga sapi di kandhang. Masyarakat Desa Kemiri memiliki kepercayaan bahwa ternak sapinya senantiasa ada yang menjaga. Oleh karena itu, masyarakat pendukung berharap semoga setelah kandhang dipasang tiga jenis sesaji kupat ini makhluk penjaga tersebut selalu bersedia menjaga ternak sapinya setiap waktu sehingga ternak sapi dijauhkan dari segala bahaya apapun. Kepercayaan ini sejalan dengan fungsi pelaksanaan tradisi larungan di Telaga Ngebel, bahwa masyarakat mengadakan tradisi untuk menyampaikan rasa terima kasih kepada yang Maha Kuasa karena telah memberikan keselamatan dan sebagai tolak balak (Rusmawati dan Suharti, 2016: 107).

Manfaat sesaji kupat bagi masyarakat pendukungnya dapat dilihat dari awal sampai selesainya prosesi Gumbregan dapat dibedakan menjadi tiga yakni manfaat spiritual, manfaat sosial, dan manfaat pelestari tradisi.

Manfaat spiritual pada tradisi Gumbregan terkait sesaji kupat, yang 
digunakan pada ritual makan sapi dan kendhuren Gumbregan adalah pengejawantahan harapan si pelaku tradisi bahwa dengan sesaji kupat luwar, si pemilik menyampaikan rasa terima kasih sebagai pangluwar ujar, sapinya sudah diberi kesehatan, keselamatan, gemuk, dan ndrebala kepada Tuhan yang Maha Esa (Bratasiswara, 2000: 380), yang telah mengizinkan sapiNya untuk dipelihara. Pemilik sapi percaya bahwa sapi yang diberikan kepadanya, sehat, gemuk sehingga dapat membantu pekerjaan pertaniannya dan memberikan kecukupan ekonomi atau sebagai tabungan. Manfaat ini dinyatakan oleh si pemilik sapi (informan 2) seperti berikut.

"Donga menika saben tiyang boten sami, nggih ming sak saged $e$ piyambak, miturut lelurine jaman riyin, ingkang cetha nyuwun kajenge sapi menika saged ngerda widada kalis saking sedaya rubeda napa mawon. Penuwunane ngoten niku, dadi kula niku ming kari nglestarekake adat." (CLW 02)

'Doa ini setiap orang tidak sama, ya sesuai dengan kemampuan sendiri, menurut leluhur zaman dulu, yang jelas memohon agar sapi-nya dapat beranak pinak, sehat terhindar dari marabahaya apapun. Permohonannya seperti itu, jadi saya hanya melestatarikan adat'.

Penjelasan tentang kepercayaan masyarakat dengan sesaji kupatmerupakan ucapan terima kasih, sebagai tolak balak, dan permohonan keselamatan untuk sapi dan pemelihara sapi tersebut diperkuat dengan tuturan informan 03 berikut.

“... Gulo kewan, kowe ketiban wuku Gumbreg kowe di Gumbregi marang bendara sira, sakwise di Gumbregi marang bendara sira kowe sowano marang Raden Bagus Umbaran, ana tarikan apa Raden Bagus Umbaran? Seka donya oleh-oleh e apa? Seka donga oleh-oleh e kupat pengluar, kupat bojo lima, kupat lepet, kupat cepuk ... Dongane nggih ming ngoten niku. Jane intine nggih niku nyuwun sageda ngerda widada bisa a slamet" (CLW 03).

‘... ini hewan, kamu pas Wuku Gumbreg, kamu digumbregi oleh juraganmu, sehabis digumbregi oleh juraganmu, kamu menghadap kepada Bagus Umbaran, ada tarikan Raden Bagus Umbaran? Dari dunia oleh-olehnya apa? Dari doa oleh-olehnya kupat pangluwar, kupat bojo lima, kupat lepet, kupat cepuk ... doanya ya hanya seperti itu. Intinya yaitu memohon agar sapi-nya dapat berkembang biak dengan baik, sehat, dan selamat' (CLW 03).

Meningkatkan hubungan sosial antarwarga. Sesaji kupat sebagai bagian dari sesaji Gumbregan pada ritual makan sapi dan kendhuren memiliki manfaat sosial. Manfaat sosial dapat terlihat pada pelaksanaan kendhuren. Sesaji kupat luwar sebagai sarana pangluwar ujar juga digunakan sebagai sarana untuk bersilaturahmi antarwarga. Kendhuren dilaksanakan sesudah waktu Magrib dengan berbagai khususnya sesaji kupat luwar sebagai bukti nadar para pemelihara sapi yang ditujukan kepada Yang maha Kuasa juga digunakan sebagai saran bersilaturahmi antar warga. Silaturahmi itu diwujudkan dengan adanya acara tukar-menukar sesaji kendhuren saat kendhuren sudah selesai didoakan oleh Pak Kaum, dilanjutkan dengan makan bersama sesaji kendhuren seperti terlihat pada Gambar 8.

Pada acara kendhuren tersebut para warga saling bertemu, bersilaturahmi, saling menukar sesaji kendhuren, kemudian 


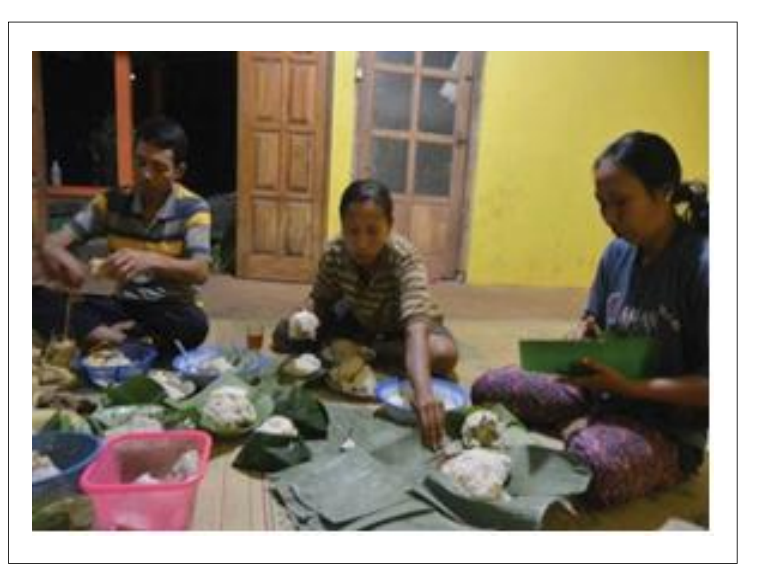

Gambar 8. Tukar-menukar Sesaji Kendhuren

dilanjutkan makan bersama menandakan adanya keakraban, kerukunan antarwarga dan adanya wadah untuk saling berinteraksi. Dengan kendhuren juga menunjukkan wujud rasa lega dari warga karena sudah selesai melaksanakan tradisi Gumbregan.

Pelestari tradisi. Pelaksanaan tradisi Gumbregan dari awal sampai akhir menunjukkan adanya ketaatan warga pada tradisi yang dilakukan oleh pendahulunya. Para pemelihara sapi merasakan manfaat meneruskan apa yang dilakukan orang tua dan leluhurnya tentang tradisi Gumbregan karena dengan melaksanakan tradisi tersebut sapi akan hidup sehat, gemuk, terlepas dari mara bahaya apapun, sehingga dapat membantu bertani untuk nggaru-ngluku, dan dapat mencukupi kebutuhan bila diperlukan. Selain itu masyarakat Desa Kemiri juga mendapat dukungan dari pemerintah tentang perlunya melaksanakan tradisitradisi di daerahnya, khususnya tradisi Gumbregan, seperti dituturkan oleh informan 01 berikut.

"Karena sekarang Dinas Kebudayaan menghendaki tinggalannya orangorang terdahulu yang sifatnya budaya itu supaya dilestarikan. Tidak bedanya dengan Gumbreg, karena kemarin dari pendamping kebudayaan Desa Kemiri itu meminta mengorek tentang acaraacara tinggalan orang dahulu, tentang Gumbreg tentang Ruwahan dan lain sebagainya" (CLW 01).

\section{SIMPULAN}

Sesaji Kupat dalam Tradisi Gumbregan di Desa Kemiri Kecamatan Tanjungsari Kabupaten Gunungkidul. Tradisi Gumbregan dilaksanakan para warga sejak leluhurnya, pada hari Selasa Wage dan Kamis Legi pada Wuku Gumbreg dari pukul 06.00 WIB sampai sesudah Magrib. Tradisi tersebut dimulai dari penyiapan sesaji dan pelaksanaan inti tradisi Gumbregan, terdiri dari ritual makan sapi dan kendhuren. Tradisi Gumbregan yang dilaksanakan oleh warga Desa Kemiri yang memelihara sapi.

Sesaji Gumbregan terdiri dari ketupat, jadah woran, pulo. Sesaji yang lebih menarik dari segi pembuatan dan maknanya adalah sesaji kupat. Persiapan sesaji pembuatan kupat dilaksanakan di rumah masing-masing para warga pemilik sapi. Adapun persiapan sesaji kupat, yang pertama harus dikerjakan oleh para warga yaitu membuat klonthongan kupat. Kelonthongan kupat dibuat dari janur, setelah itu kupat diisi beras yang sudah dibersihkan kemudian dimasukkan ke dalam klonthongan kira-kira setengah dari besar klonthongan kupat, kemudian direbus dengan air selalu di atas kupat, kira-kira empat jam sampai masak. Sesaji kupat yang dibuat terdiri atas kupat luwar, kupat lepet, kupat cepuk, dan kupat bojo lima.

Makna simbolis sesaji kupat luwar yang digunakan sebagai sesaji ritual ngalungi sapi sebagai simbol bahwa sapi dikalungi atau diubedi kupat luwar menyimbolkan sebagai pager atau benteng agar terbebas dari segala mara bahaya. Kupat luwar sebagai pakan ternak sebagai 
pangluwar ujar atau nadar, yaitu menjadi simbol atau bukti sahnya suatu janji atau ujar pemilik sapi karena ternaknya selamat, ndrebala, dan selanjutnya pemilik dan ternaknya dijauhkan dari mara bahaya apapun, selalu mendapat lindungan dari Tuhan Yang Maha Esa, serta masyarakat pendukung bertaninya selalu berhasil dengan memuaskan. Adapun sesaji kupat lepet, kupat cepuk, dan kupat bojo lima yang hanya ditujukan kepada leluhur dan makhluk yang menjaga kandhang sebagai simbol penghormatan, penyampaian rasa terima kasih, dan permohonan agar sapi dan pemeliharanya selalu dilindungi dari mara bahaya apapun sehingga sapi dan pemeliharanya selalu sehat, tenteram, selamat, dan terbebas dari gangguan apapun. Manfaat kupat pada tradisi Gumbregan bagi masyarakat pendukungnya yaitu manfaat spiritual, manfaat sosial ekonomi, dan manfaat pelestari tradisi.

\section{DAFTAR PUSTAKA}

Bratasiswa, H. 2000. Bauwarna Adat Tata Cara Jawa. Buku 1 (A-M). Jakarta: Yayasan Suryasumirat.
Moleong, L. J. 2006. Metodologi Penelitian Kualitatif. Bandung: Remaja Rosdakarya.

Danandjaja, J. 1986. Folklor Indonesia. Jakarta: Pustaka Grafitipers.

Herusatoto, B. 2008. Simbolisme Jawa. Yogyakarta: Ombak.

Mulyani, H., Widyastuti, S. H., \& Ekowati, V. I. 2016. "Tumbuhan Herbal sebagai Jamu Pengobatan Tradisional terhadap Penyakit dalam Serat Primbon Jampi Jawi Jilid I". Humaniora, 21(2), 73-91.

Moertjipto, dkk. 1996/1997. Wujud, Arti, dan Fungsi Puncak-Puncak Kebudayaan Lama dan Asli Bagi Masyarakat Pendukungnya di Daerah Istimewa Yogyakarta. Yogyakarta: Depdikbud.

Poerwadarminta, W. J. S. 1939. Baoesastra Djawa. Batavia: B. Wolters Uitgevers Maatschappij Groningen.

Rusmawati, \& Suharti. 2016. "Tradhisi Larungan Buceng Agung di Telaga Ngebel sebagai Sarana Penarik Wisatawan". Humaniora, 21(2), 99 108. 